\title{
AULAS DE EDUCACIÓN ESPECIAL EN ESPAÑA: ANÁLISIS COMPARADO ${ }^{1}$
}

\section{Special classrooms in Spain: comparative analysis}

\author{
Rogelio Martínez Abellán \\ Universidad de Murcia. Facultad de Educación. Departamento de Didáctica y Organización \\ Escolar. Campus Universitario de Espinardo. Espinardo, 30100 Murcia \\ rogeliom@um.es \\ Mónica Porto Currás \\ Universidad de Murcia. Facultad de Educación. Depto. de Didáctica y Organización Escolar \\ Carlos F. Garrido GIL \\ Universidad de Murcia. Facultad de Educación. Depto. de Didáctica y Organización Escolar
}

Recepción: 5 de abril de 2017

Aceptación definitiva: 1 de marzo de 2019

Resumen: En este artículo se presenta un análisis comparativo de la filosofía y organización con la que se desarrollan las aulas para alumnos con necesidades educativas especiales dentro de los centros ordinarios, en las diferentes comunidades autónomas españolas. Para ello, se hace un recorrido por la legislación que las regula en cada comunidad autónoma, comparando nomenclatura, características y ratio del alumnado que escolarizan, profesionales que intervienen, requisitos para su implementación, así como la finalidad con la que son creadas. Los principales resultados apuntan que las diferentes comunidades autónomas ofrecen alternativas que difieren en aspectos importantes tales como la consideración de estas aulas como unidades que sustituyen a los centros de educación especial -pero cumplen las mismas funciones- o como espacios dentro de los centros ordinarios en los que se busca una inclusión progresiva del alumnado que escolarizan. Aunque son aulas creadas para buscar la mayor inclusión del alumnado con necesidades educativas severas, las normativas de las diferentes comunidades autónomas no siempre se ajustan a esta finalidad.

Palabras Clave: aulas especializadas; aulas abiertas; alumnado con necesidades educativas especiales; pluridiscapacidad; inclusión; comunidades autónomas; modalidades de escolarización.

1 Este trabajo forma parte de la investigación denominada "Medidas específicas de atención a la diversidad: evaluación de aulas específicas en la Región de Murcia” (Edu2016-78102-r), financiada por la Agencia Estatal de Investigación, y llevada a cabo por el Grupo de Investigación "Educación Inclusiva: una escuela para todos" (EDUIN, E-073-02) de la Universidad de Murcia 
АвSTRAст: This article presents a comparative analysis of the philosophy and organization with which special classrooms are developed for students with special educational needs within ordinary schools in the different Spanish autonomous communities. To do this, a tour is made through the legislation that regulates them in each autonomous community, comparing their nomenclature, characteristics and ratio of the students they attend, professionals involved, requirements for its implementation, as well as the purpose with which they are created. The main results indicate that the different autonomous communities offer alternatives that differ in important aspects such as the consideration of these classrooms as units that replace the special education centers, but they fulfill the same functions, or as spaces within the ordinary centers in the which seeks a progressive inclusion of students who attend. Although they are classrooms created to seek the greater inclusion of students with severe educational needs, the regulations of the different autonomous communities do not always fit this purpose.

KEY WORDS: special classrooms; open classrooms; students with special educational needs; multiple disabilities; inclusion; autonomous communities; modalities of schooling.

\section{Introducción}

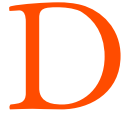

ENTRO DEL CENTRO ORDINARIO PODEMOS ENCONTRAR UN ESPACIO, aula especializada, aula abierta o aula de educación especial, en función de la comunidad autónoma, creado para ofrecer a los alumnos con necesidades educativas especiales la posibilidad de contar con opciones de escolarización más inclusivas. Es una medida de atención educativa de carácter extraordinario que, desde los principios de normalización e inclusión, va destinada a determinados alumnos con necesidades educativas especiales graves y permanentes, que precisen de apoyo extenso y generalizado en todas las áreas del currículo.

La modalidad de escolarización aula de educación especial comenzó a darse en la década de los ochenta (Ruiz, 2007), donde se empezaron a crear aulas de educación en centros ordinarios en las poblaciones alejadas de las grandes ciudades, o muy lejanas a centros de educación especial. De esta manera se generaba un recurso específico, dentro de un colegio ordinario, para dar respuesta al alumnado con discapacidad y, a la vez, permitía que pudiesen compartir algunas actividades con el resto de compañeros del centro, como recreos y momentos de descanso, excursiones, actividades extraescolares o complementarias e, incluso, algunas materias con contenido curricular.

Para poder entender cómo surgen esta modalidad de escolarización y comprender algunas de las diferencias aún presentes en las diferentes comunidades autónomas, presentamos un breve recorrido histórico por la normativa estatal con relación a sus orígenes en las aulas de educación especial.

En la Ley General de Educación de 1970, la educación especial se entiende como una modalidad específica, es decir, como un sistema educativo paralelo al de la educación ordinaria, regido por sus propias normas y por un currículo específico distinto al general. En la práctica solo tenían acceso a este sistema los alumnos menos afectados que no podían seguir el ritmo de la educación ordinaria, puesto que la escolarización

(C) Ediciones Universidad de Salamanca / CC BY-NC-ND

Siglo Cero, vol. 50 (3), n. ${ }^{\circ}$ 271, 2019, julio-septiembre, pp. 89-120 
no era obligatoria. La Ley General de Educación preveía igualmente la creación de aulas de educación especial en centros ordinarios para los alumnos deficientes ligeros como medida más avanzada. Respecto a la manera de atender a estos alumnos en el artículo 51 de la Ley se indica lo siguiente: "La educación de los deficientes e inadaptados, cuando la profundidad de las anomalías que padezcan lo haga absolutamente necesario se llevará a cabo en centros especiales, fomentándose el establecimiento de unidades de educación especial en centros docentes de régimen ordinario para los deficientes leves cuando sea posible”.

La Constitución española (1978), en sus artículos 14 y 27, define la educación básica como un derecho y un deber universal y gratuito. Esto supone que todos los alumnos entre seis y dieciséis años, sea cual sea su situación, deben estar escolarizados. Así, el sistema educativo español se organiza para dar respuesta a la diversidad del alumnado, atendiendo a sus necesidades educativas, incluso cuando estas son especiales, estableciendo que, en esa circunstancia, la atención al alumnado debe hacerse en base a los principios de integración y normalización, lo que implica el establecimiento de medidas que permitan la inclusión de dicho alumnado en los centros ordinarios, velando a la vez por que todos y cada uno de los alumnos alcancen el mayor desarrollo personal que sus capacidades posibiliten.

Por otro lado, el Real Decreto 334/1985, de Ordenación de la Educación Especial, define la educación especial como parte integrante del sistema educativo; se dirige a las personas afectadas por disminuciones físicas, psíquicas y sensoriales o por inadaptaciones y establece distintas modalidades educativas: atención educativa temprana, centros ordinarios en régimen de integración, centros especiales o específicos, unidades de educación especial en centros ordinarios.

En 1990, con la LOGSE, la educación especial se reconfigura. Establece la educación obligatoria para todo el alumnado hasta los dieciséis años, introduce la educación especial dentro del sistema educativo ordinario (un único sistema educativo que engloba a la totalidad del alumnado). E introduce por primera vez en la legislación española el concepto de alumno con necesidades educativas especiales. Del mismo modo, prevé la creación de unidades de educación especial en los centros ordinarios para deficientes leves y centros de educación especial para deficientes e inadaptados graves. Concretamente, en su artículo 37 se recoge que la escolarización en unidades o centros de educación especial solo se llevará a cabo cuando las necesidades del alumno no puedan ser atendidas en un centro ordinario.

En el capítulo v de la LOGSE, el artículo 36 establece: “El sistema educativo dispondrá de los recursos necesarios para que los alumnos con necesidades educativas especiales, temporales o permanentes, puedan alcanzar, dentro del mismo sistema, los objetivos establecidos con carácter general para todos los alumnos”. Igualmente, en el artículo 37.4 se indica la excepcionalidad de que no fuesen atendidas sus necesidades educativas en un centro ordinario: "La escolarización en unidades o centros de educación especial sólo se llevará a cabo cuando las necesidades del alumno no puedan ser atendidas por un centro ordinario. Dicha situación será revisada periódicamente, de modo que pueda favorecerse, siempre que sea posible, el acceso de los alumnos a un régimen de mayor integración”. 
En este sentido, las aulas de educación especial ubicadas en centros ordinarios desarrollarán los mismos objetivos educativos que los impartidos en los centros específicos y para ello se organizarán las enseñanzas correspondientes al periodo de formación para la transición a la vida adulta y laboral. Se entiende así el aula de educación especial como una opción de escolarización que favorece la inserción social y comunitaria, mantiene la vinculación con su entorno y con su familia y es la más adecuada para aquellos escolares que no requieren atención constante por parte de profesionales especializados, diferentes al profesorado, ni uso de equipamientos e instalaciones específicas que normalmente solo están disponibles en los centros específicos de educación especial (Ramírez, 2010).

En el año 1995 se publica el Real Decreto 696/1995 (26 de abril) de ordenación de la educación de los alumnos con necesidades educativas especiales. Este decreto regula los aspectos relativos a la ordenación, la planificación de los recursos y la organización de la atención educativa a los alumnos con necesidades educativas especiales temporales o permanentes cuyo origen puede atribuirse, fundamentalmente, a la historia educativa y escolar de los alumnos, a condiciones personales de sobredotación o a condiciones igualmente personales de discapacidad (sensorial, motórica o psíquica). Todo ello en desarrollo de los artículos 36 y 37 de la LOGSE. Asimismo, este decreto determina que las necesidades educativas de los alumnos pueden ser atendidas en centros ordinarios en centros específicos solo cuando las necesidades no puedan atenderse en los centros ordinarios, y en centros hospitalarios y de rehabilitación, a través de la creación de servicios escolares y en base a la evaluación del alumno y del contexto. En este sentido, en su artículo 19 establece la posibilidad de habilitar en las zonas rurales aulas en centros ordinarios para la educación de los alumnos con necesidades educativas especiales permanentes asociadas a condiciones personales de discapacidad que requieran, de acuerdo con la evaluación y el dictamen realizados por los equipos de orientación educativa y psicopedagógica, adaptaciones significativas y en grado extremo en las áreas del currículo oficial que les corresponda por su edad y cuando se considere por ello que sería mínimo su nivel de adaptación y de integración social en un centro escolar ordinario.

Con la aprobación de la Ley Orgánica 2/2006, de 3 de mayo, de Educación (LOE), se produce un cambio cualitativo. Esta ley determina como principios educativos la calidad de la educación para todo el alumnado, independientemente de sus condiciones y circunstancias, y la equidad como garante de la igualdad de oportunidades, la inclusión educativa y la no discriminación, puesto que actúa como elemento compensador de las desigualdades personales, culturales, económicas y sociales, poniendo especial atención en aquellas que derivan de discapacidad. Además, en su artículo 74 establece que la escolarización del alumnado que presente necesidades educativas especiales se regirá por los principios de normalización e inclusión y se asegurará su no discriminación y la igualdad efectiva en el acceso y la permanencia en el sistema educativo, pudiendo introducirse medidas de flexibilización de las distintas etapas educativas cuando se considere necesario. La escolarización de este alumnado en unidades o centros de educación especial, que podrá extenderse hasta los veintiún años, solo se llevará a cabo cuando sus necesidades no puedan ser atendidas en el marco de las medidas de atención a la diversidad de los centros ordinarios. 
Con estas premisas, se crean en algunas comunidades autónomas aulas de educación especial en los centros ordinarios que, a diferencia de las tradicionales unidades sustitutorias de los centros de educación especial, se configuran como un medio de respuesta más abierto y normalizado al alumno con necesidades educativas especiales permanentes, al contemplar la adscripción de este alumnado en un grupo de referencia ordinario.

Es cierto que estar escolarizado en un centro ordinario proporciona beneficios para el alumnado con discapacidad y el resto de la diversidad de estudiantes. Pero que exista un aula de educación especial en el centro ordinario no supone que las prácticas que se den sean inclusivas o se realicen interacciones periódicas entre el alumnado del aula de educación especial y el resto de compañeros del centro. El lugar donde se establezcan las instalaciones del aula de educación especial forma parte de una estrategia para fomentar la interacción en espacios y tiempos comunes con el resto de personas del centro. Si el aula se ubica en un lugar apartado, de poco tránsito, donde el alumnado permanezca apartado, no permitirá las relaciones con otros compañeros ni será visible para la comunidad educativa (Ramírez, 2010). La pretensión es que debe intentarse llevar a cabo una inclusión parcial o total en el aula ordinaria (Martínez, 2000). Por ello, además de la importancia de ubicar el aula de educación especial en el centro ordinario, es necesario planificar los momentos y espacios donde se pueden llevar a cabo acciones inclusivas con el alumnado escolarizado en ella (Pérez, Guillén, Pérez, Jiménez y Bonilla, 2008).

A pesar de que esta medida lleva ya un tiempo funcionando en diferentes comunidades autónomas, apenas se encuentran trabajos publicados en cuanto a su organización, funcionamiento y respuesta educativa o las diferencias que puedan existir entre ellas. Por ello, en este artículo se expone una comparativa entre la organización de estas aulas en las diferentes comunidades autónomas españolas, revisando en cada una de ellas la legislación que las regula.

\section{Metodología}

Para realizar este análisis comparativo se ha procedido a efectuar una búsqueda de la normativa que regula las aulas de educación especial y sus características diferenciales en las bases de datos legislativas de las diferentes comunidades autónomas españolas. Se ha realizado una selección de esta normativa atendiendo a aquellos decretos y órdenes que establecían claramente aspectos relativos a los indicadores que habíamos seleccionado previamente para su comparación: nomenclatura, características y número de alumnos que escolarizan, profesionales que integran estas aulas y condiciones que se deben dar para contar con estas aulas en los centros. En algunos casos, esta información se encontró en resoluciones en las que dictan instrucciones o circulares enviadas por las direcciones de centros escolares autonómicas, pero solo se han incluido estas referencias si esa información no estaba presente en las órdenes o decretos más generales. 


\section{Resultados}

En este apartado se presentan, de forma detallada por comunidad autónoma, las especificidades de estas aulas para, a continuación, hacer un análisis de las principales coincidencias y diferencias encontradas. Para ordenar la información, se presentan las comunidades autónomas por orden alfabético.

\subsection{Andalucía}

La Consejería de Educación de la Junta de Andalucía define esta modalidad como aulas específicas de educación especial en centros ordinarios. Según el Decreto 147/2002, está destinada al alumnado con necesidades educativas especiales permanentes que requieran adaptaciones significativas y en grado extremo en las áreas del currículo oficial que les corresponda por su edad. Hasta los dieciséis años pueden estar escolarizados en estas aulas, aunque esta escolarización se puede prorrogar hasta los veinte años. En cuanto a la ratio no se establece un número fijo, ya que dependerá de las necesidades del alumnado: variando entre tres y cinco alumnos por aula para trastornos generalizados del desarrollo, de seis a ocho para personas con discapacidad sensorial o de ocho a diez para personas con movilidad reducida.

Las aulas específicas de educación especial en centros ordinarios han de desarrollar los mismos objetivos educativos que los centros específicos de educación especial, procurando la mayor integración posible de los alumnos en ellas escolarizados en las actividades complementarias y extraescolares del centro. Las adaptaciones curriculares que se precise llevar a cabo tienen en cuenta la edad del alumno y su proceso educativo y evolutivo, con las mismas prioridades establecidas en el caso de los centros específicos de educación especial. La diferencia se establece en la adopción de las medidas necesarias para facilitar el proceso de integración de este alumnado en los centros ordinarios, garantizando la existencia de espacios y tiempos compartidos con el resto de la comunidad escolar. Excepcionalmente, en aquellas localidades donde no exista oferta de educación secundaria sostenida con fondos públicos, la Consejería de Educación y Ciencia puede autorizar la continuidad de la escolarización de alumnado con discapacidad en aulas específicas de educación especial de colegios de educación primaria.

La escolarización ajustada para el alumnado, por ejemplo con trastornos generalizados del desarrollo, está en función de los recursos con los que cuenta el centro para dar una respuesta adecuada a las necesidades educativas. Si las características del aula ordinaria no pueden atender las demandas del alumnado con necesidades educativas, es cuando las aulas específicas de educación especial en centros ordinarios se convierten en la alternativa que mantenga al alumno en el centro, favoreciendo la interacción con otros alumnos en diversas actividades (Pérez et al., 2008).

\subsection{Aragón}

En la Comunidad Autónoma de Aragón se mencionan las unidades de educación especial en centros ordinarios para alumnado con necesidades educativas especiales 
de grado 3 en la Orden de 30 de julio de 2014, de la Consejería de Educación, Universidad, Cultura y Deporte, por la que se regulan las medidas de intervención educativa para favorecer el éxito y la excelencia de todos los alumnos de la Comunidad Autónoma de Aragón desde un enfoque inclusivo.

En la Orden de 25 de junio de 2001, del Departamento de Educación y Ciencia, por la que se regula la acción educativa para el alumnado que presenta necesidades educativas especiales derivadas de condiciones personales de discapacidad física, psíquica o sensorial o como consecuencia de una sobredotación intelectual, se establece que se pueden establecer unidades para los alumnos afectados de trastornos generalizados del desarrollo que no lleven asociada una deficiencia mental en Educación Primaria. Excepcionalmente, y para los alumnos con trastornos muy graves por déficit de atención y comportamiento perturbador, el Departamento de Educación y Ciencia puede poner en funcionamiento unidades específicas en centros ordinarios. En ambos casos, el procedimiento a seguir incluye los siguientes informes: informe del equipo de orientación educativa y psicopedagógica del sector, informe de la inspección educativa y propuesta del director del Servicio Provincial de Educación y Ciencia a la Dirección General de Renovación Pedagógica. En cualquier caso, se pretende que dicha escolarización tenga un carácter transitorio, promoviendo la participación de estos alumnos en el mayor número posible de las actividades que organice el centro.

En el caso de centros de Educación Secundaria con unidades de educación especial, es obligatoria la inclusión de la programación del conjunto de actuaciones previstas para atender al alumnado con necesidades educativas especiales en sus proyectos curriculares de centro. Se establece que todo el profesorado del centro debe promover la organización de actividades comunes para todo el alumnado, buscando las mayores oportunidades de interacción social.

En cualquier caso, las unidades de educación especial en centros ordinarios desarrollan, con relación al alumnado, las mismas funciones de los centros de educación especial. Se establecen las adaptaciones curriculares necesarias, teniendo en cuenta la edad de los alumnos y su proceso educativo y evolutivo, con las mismas prioridades reguladas en el caso de los centros de educación especial.

\subsection{Asturias, Cantabria, La Rioja y Castilla y León}

La legislación de estas comunidades también establece la posibilidad de crear unidades de educación especial (aulas sustitutorias) en los centros educativos ordinarios de Educación Primaria y Secundaria para atender a alumnado con necesidades específicas graves, que no pueden ser atendidos mediante las medidas de atención a la diversidad en los centros ordinarios, pero no se concreta nada más sobre la organización de estas aulas. Las unidades de educación especial en centros ordinarios realizan funciones de centro de educación especial.

\subsection{Baleares}

En Baleares, el primer centro de educación especial para el alumnado con trastorno generalizado del desarrollo se puso en marcha en 1980. Poco después se comenzaron

(C) Ediciones Universidad de Salamanca / CC BY-NC-ND

Siglo Cero, vol. 50 (3), n. ${ }^{\circ}$ 271, 2019, julio-septiembre, pp. 89-120 
a llevar a cabo acciones de escolarización combinada, hasta que en 1990 se crearon en esta comunidad autónoma las primeras aulas de educación especial dentro de los centros ordinarios (Morueco et al., 2008). Esta modalidad de escolarización recibió el nombre de aula sustitutoria de centro específico, aunque actualmente la Consejería de Educación, Cultura y Universidades del Gobierno de las Islas Baleares la denomina unidad educativa con currículo propio inserta en centros ordinarios, sin dependencia de los centros de educación especial, según la Orden de la Consejería de Educación y Cultura, de 29 de enero de 2009 , por la cual se regulan la creación y el funcionamiento de las unidades educativas con currículum propio. Estas aulas pueden tener hasta siete alumnos, aunque la ratio puede disminuir si alguno de sus integrantes tiene una necesidad de apoyo generalizado, pudiendo estar escolarizados hasta los dieciocho años.

La modalidad está destinada al alumnado con necesidades educativas asociadas a discapacidad intelectual con o sin trastorno de personalidad, a trastornos generalizados del desarrollo, a discapacidad motriz o a plurideficiencias, que no puedan seguir el currículo del aula ordinaria, pero no por ello deban estar en un entorno segregado, pudiendo llevar a cabo un proceso educativo en la unidad educativa de currículo propio con un tutor a cargo y participar en otras actividades del centro ordinario (Merino, 2008).

Tal y como establece la normativa citada, las unidades educativas con currículum propio deben contar con un equipo docente compuesto por maestro de educación especial o de la especialidad de pedagogía terapéutica con funciones de tutor y un auxiliar técnico educativo (ATE). Asimismo, el maestro de audición y lenguaje asignado al centro con carácter ordinario y un especialista en fisioterapia dispondrán de un horario de atención proporcional para atender las necesidades del alumnado que lo requiera. La unidad educativa puede contar con la participación de otros profesores del centro cuando se considere preciso.

El número de alumnos máximo en estas unidades es de siete, si bien esta ratio puede ser menor si entre el alumnado escolarizado la mayoría tiene necesidades educativas especiales asociadas a discapacidad motriz, a autismo o a trastorno de la personalidad.

Los centros que cuentan con esta unidad educativa serán de atención preferente para los equipos de orientación educativa y psicopedagógica del sector, en caso de no tener un orientador de centro. El orientador debe asistir un día por semana para colaborar en el apoyo que la unidad educativa requiera, sin detrimento de la atención ordinaria al centro en su conjunto.

\subsection{Canarias}

En la Comunidad Autónoma Canaria las aulas de educación especial en centro ordinario reciben la denominación de aulas enclave, que adquieren su nombre debido a su disposición física, ya que son clases cuyo “enclave” se encuentra en un centro ordinario de infantil, primaria o secundaria (Alemán, 2008).

Esta modalidad de escolarización comenzó a funcionar en la provincia de Las Palmas durante el curso escolar 1994-1995 en un centro de Primaria de la isla de 
Fuerteventura y, posteriormente, durante el curso 1999-2000 se crea la primera de las aulas enclave en la etapa de Secundaria, enfocada al alumnado con necesidades educativas por motivos de discapacidad intelectual, trastornos generalizados del desarrollo y otras discapacidades físicas o sensoriales, que requiere de adaptaciones curriculares que se alejen significativamente del currículo ordinario, posibilitando la participación en actividades inclusivas con el resto de compañeros (Auyanet et al., 2004).

La Consejería de Educación, Universidades y Sostenibilidad del Gobierno de Canarias define las aulas enclave, según el Decreto 104/2010, como comunidades de escolarización situadas en centros escolares ordinarios, donde se ofrece una respuesta educativa al alumnado con necesidades educativas que precisa de adaptaciones que se apartan significativamente del currículo en la mayor parte o todas las áreas o materias y precisa de la utilización de recursos extraordinarios. Esta escolarización no supone una situación irreversible, ya que tiene carácter revisable y puede prorrogarse hasta los veintiún años de edad.

En cuanto a las ratios, la Consejería propuso un número variable de alumnos dependiendo de las necesidades que presenten, siendo de tres a cuatro para alumnado gravemente afectado; de cuatro a cinco para el alumnado con escaso nivel de autonomía personal y que su referente curricular esté en Educación Infantil, y de seis a ocho para el alumnado con autonomía suficiente que no requiera de la supervisión constante. Para el agrupamiento del alumnado se tienen en cuenta las características propias de cada uno de ellos, atendiendo a criterios pedagógicos, niveles cognitivos, tipo de discapacidad, necesidades educativas, etc.

El equipo docente debe estar compuesto por profesionales como profesorado de apoyo a las necesidades específicas de apoyo educativo (NEAE), auxiliar educativo y maestro de taller, dependiendo de la etapa educativa. Esta modalidad de escolarización tiene el objetivo de dar un proceso de enseñanza lo más adaptado posible a las características del alumnado con discapacidad, a través de un tutor que cuenta con la ayuda de un auxiliar para un grupo reducido, y siguiendo el principio de sectorización, acercando el recurso al entorno donde reside el alumnado del aula enclave (Núñez, 2009).

Respecto al currículo, tienen una concreción curricular adaptada denominada Programa de tránsito a la vida adulta en la Comunidad Autónoma de Canarias (Gónzalez y Cámara, 2006), que desarrolla las competencias básicas en el ámbito de la autonomía personal y social en la etapa de Primaria, y un programa de tránsito a la vida adulta en la etapa de Secundaria.

La modalidad de escolarización de aulas enclave dentro de los centros ordinarios ha originado un mayor esfuerzo de organización, en el aula y el centro donde se encuentran ubicadas, pero ha repercutido en la normalización y sensibilización de la comunidad educativa en torno a la inclusión de su alumnado (Auyanet et al., 2004).

\subsection{Castilla-La Mancha}

En Castilla-La Mancha se regulan en 2002 las unidades de educación especial en centros ordinarios (Decreto 138/2002), entendidas como "un medio de respuesta más 
abierto y normalizado al alumnado con necesidades educativas especiales permanentes psíquicas moderadas, severas y profundas, a graves alteraciones de la personalidad y a plurideficiencias”. En estas unidades los referentes curriculares son los mismos que en los centros de educación especial, con la única diferencia de que se procurará una participación del alumnado escolarizado en estas unidades en todas aquellas actividades del centro educativo que favorezcan su integración.

Además, en enero de 2014 se crean en esta comunidad las aulas abiertas especializadas para alumnado con trastornos del espectro del autismo. A ellas asisten un máximo de cuatro a seis alumnos en Educación Infantil y Primaria y de cuatro a siete en Educación Secundaria. Las aulas abiertas especializadas son atendidas por un maestro especialista en pedagogía terapéutica que coordina el funcionamiento del aula, un maestro especialista en audición y lenguaje que dedica la totalidad del horario al aula y un auxiliar técnico educativo que se responsabiliza de la atención de este alumnado en los recreos, el comedor escolar y los períodos previo y posterior a la comida (cuando el centro cuente con ese servicio complementario), así como de cualquier otra necesidad derivada de la situación personal de los alumnos. Se pretende que el alumnado solo pase en esta aula el tiempo necesario, priorizando que la mayor parte de la jornada escolar se encuentre en su clase de referencia con sus compañeros.

\subsection{Cataluña}

En esta comunidad autónoma se pueden encontrar diferentes tipos de aulas en centros ordinarios para atender al alumnado con necesidades educativas especiales:

1. Las unidades de educación especial, reguladas por el Decreto 299/1997 sobre la atención educativa al alumnado con necesidades educativas especiales, creadas para escolarizar al alumnado con necesidades educativas especiales que no puede ser atendido en aulas ordinarias y no existen centros de educación especial próximos a su domicilio. En estas unidades, se establecía una ratio mínima de tres alumnos y ocho como máximo.

2. Aulas abiertas, destinadas al alumnado de tercer o cuarto curso de Eso que por causas diversas presenten deficiencias significativas en sus aprendizajes, bajo nivel de autoestima, desmotivación por la actividad escolar y absentismo. La ordenación de estas aulas abiertas se plantea bajo los criterios de organizar de manera globalizada los aprendizajes básicos y fundamentales con una metodología más práctica y actividades más manipulativas; reducir el número de profesores que intervienen en el grupo; utilizar las TIC como herramienta de aprendizaje; fomentar el trabajo cooperativo; reforzar la atención personalizada, y compaginar actividades en el aula específica con actividades con el grupo clase ordinario. En definitiva, se pretende generar un entorno escolar que aumente la motivación del alumnado mediante una metodología más integradora y activa. 
3. Unidades de apoyo a la educación especial (USEE), entendidas como recursos para facilitar la atención educativa y promover la participación en entornos escolares ordinarios a los alumnos con discapacidades intelectuales, trastornos generalizados del desarrollo y trastornos del espectro autista. En el documento de 2008 en el que se establecen Orientaciones al entorno de las unidades de apoyo a la educación especial se establece que "son unos recursos organizativos de atención a los alumnos que presentan NEE susceptibles de ser escolarizados en centros específicos con el fin de favorecer su integración en el entorno ordinario". En este caso, la ratio se concreta entre cinco y diez alumnos.

La atención de estos alumnos se puede llevar a cabo de la siguiente manera:

- En el aula ordinaria compartiendo con la usEe (con porcentajes equivalentes).

- En la unidad de apoyo a la educación especial a tiempo total (no recomendable).

- En fórmulas organizativas más flexibles sin perder de vista las actividades generales para todos los alumnos del centro.

En cuanto a los profesionales destinados a ellas, en cada una hay dos psicopedagogos y un educador social.

4. Unidades de escolarización compartida (UEC), planteadas como un recurso destinado a garantizar la respuesta educativa necesaria al alumnado con necesidades específicas de apoyo educativo derivadas de una inadaptación extrema al medio escolar en los centros que imparten Educación Secundaria Obligatoria. De este modo, las unidades de escolarización compartida posibilitan, de manera excepcional, seguir la etapa de Eso en un grupo reducido con las correspondientes adaptaciones curriculares individualizadas. La enseñanza que se imparte en las unidades de escolarización compartida tiene un carácter globalizador y de aplicación práctica, teniendo en cuenta la promoción de habilidades que faciliten la inserción social y laboral. Asimismo, estas unidades priorizan la adquisición de las habilidades necesarias para la readaptación del alumnado al medio escolar ordinario. La escolarización en estas unidades es siempre con carácter temporal, siendo revisada y evaluada trimestralmente a lo largo del curso escolar.

\subsection{Comunidad Valenciana}

La Consejería de Educación, Cultura y Deportes de la Generalitat Valenciana, según el Decreto 39/1998, define esta modalidad como aulas específicas de educación especial, destinadas al alumnado que requiera adaptaciones que se alejen en grado extremo del currículo. Según la Consejería, la creación de estas unidades responde preferentemente al principio de sectorización, cuando la demanda requiera acercar esta modalidad a zonas rurales o poblaciones alejadas.

El aula específica de educación especial debe ser una opción a tener en cuenta cuando el alumnado no pueda recibir la atención diferenciada e individualizada en el contexto del aula ordinaria (Lledó, Fernández y Grau, 2006). Aunque se ubica en un entorno socializador, el aula específica puede derivar en un recurso aislado, por 
lo que los centros educativos con aula específica deben recoger, en su proyecto y en el plan de atención a la diversidad, los objetivos y actividades que se plantean para el alumnado, con la finalidad de facilitar la integración.

Si nos centramos en la modalidad de escolarización combinada, encontramos en el ámbito educativo valenciano una variante denominada aulas de comunicación y lenguaje (cyL), presentadas bajo el formato de programa experimental propuesto desde la Consellería de Educación. Las aulas cyl han sido definidas por Bellver, Díez, López y Navarro (2009), como: “unidades específicas de educación especial ubicadas en centros ordinarios con carácter experimental y destinadas a dar una respuesta educativa adecuada a determinadas necesidades del alumnado con TEL o trastorno generalizado del desarrollo" (p. 3). Sus objetivos principales se especifican en las Instrucciones de la Dirección General de Ordenación y Centros docentes de 10 de mayo de 2012, centrándose en favorecer el desarrollo personal y ofrecer la oportunidad de integración social. El equipo docente de estas aculas está compuesto por educador en educación especial y especialistas en pedagogía terapéutica y en audición y lenguaje.

Existen dos modalidades de escolarización en un aula cyl: la primera implica permanecer en esta aula un porcentaje igual o superior al cuarenta por ciento del horario; mientras que la segunda consiste en permanecer como mínimo el sesenta por ciento del horario en un aula ordinaria, lo que supone la capacidad de aprender utilizando el currículo ordinario adaptado.

Entre las características de las aulas cyl se puede señalar la organización espaciotemporal por rincones, basándose en una sucesión de rutinas diarias con claves visuales (Bellver y otros, 2009).

\subsection{Extremadura}

En Extremadura las aulas abiertas se regulan por la Orden de 6 de julio de 2012, donde se definen como:

Aulas especializadas, que constituyen una medida de atención educativa de carácter extraordinario que, desde los principios de normalización e inclusión, va destinada a determinados alumnos, con necesidades educativas especiales graves y permanentes, que precisen de apoyo extenso y generalizado en todas las áreas del currículo. Son aulas que se encuentran ubicadas en un centro ordinario, siendo una modalidad de escolarización para aquellos alumnos que precisan adaptaciones curriculares muy significativas pero que pueden participar de actividades socializadoras del centro.

Esta modalidad de escolarización está destinada a alumnado con necesidades educativas especiales graves y permanentes derivadas de discapacidad psíquica severa, pluridiscapacidad, discapacidad motórica grave asociada a discapacidad psíquica, discapacidad psíquica con alteraciones graves de comunicación o trastornos del espectro autista y otros trastornos generalizados del desarrollo.

Además, y en función de las características del alumnado, las aulas abiertas se dividen en generales (para alumnado que reúne las necesidades antes citadas) o específicas, que pueden agruparse según la tipología del alumnado en:

(C) Ediciones Universidad de Salamanca / CC BY-NC-ND

Siglo Cero, vol. 50 (3), n. ${ }^{\circ}$ 271, 2019, julio-septiembre, pp. 89-120 
- Aulas abiertas que escolaricen, preferentemente, a alumnado con discapacidad motora severa, asociada a discapacidad psíquica moderada o severa y con graves dificultades en la comunicación.

- Aulas abiertas que escolaricen, preferentemente, a alumnado con trastorno del espectro autista u otros trastornos generalizados del desarrollo, asociado a discapacidad psíquica severa (y que no puede ser atendido convenientemente en el aula ordinaria).

- Otras aulas abiertas específicas que escolaricen, preferentemente, a alumnado con discapacidad auditiva severa o discapacidad visual severa y otras discapacidades asociadas, o cualquier otra condición específica en la que pudieran coincidir un número suficiente de alumnos.

La edad máxima de permanencia en estas aulas abiertas en centros de Educación Infantil y Primaria se sitúa, con carácter general, en los catorce años, si bien, excepcionalmente, en la zona rural pueden permanecer escolarizados hasta los dieciséis años. El alumnado mayor de doce años debe escolarizarse en centros de Educación Secundaria que dispongan de los recursos regulados, siendo la edad máxima de permanencia en dichas aulas hasta los dieciocho años.

Los programas de formación para la transición a la vida adulta se imparten, con carácter general, en centros de educación especial. No obstante, pueden impartirse estos programas en centros de Educación Secundaria que dispongan de aulas abiertas previa autorización de la administración educativa.

La ratio del alumnado escolarizado en un aula abierta puede oscilar entre tres y seis alumnos, si bien el establecimiento de la ratio tiene en cuenta las siguientes variables:

a) Para el alumnado gravemente afectado o con presencia asociada de trastornos graves de conducta, que requiere atención constante para evitar situaciones perjudiciales que afecten la integridad física propia o de sus compañeros, los grupos serán de tres o cuatro alumnos.

b) Para el alumnado con escaso nivel de autonomía personal y que necesite supervisión y ayuda constante para el desarrollo de hábitos y que, además, su referente curricular esté en Educación Infantil, los grupos serán de cuatro o cinco alumnos.

c) Para el alumnado que esté desarrollando la concreción curricular adaptada para Educación Primaria equivalente al primer ciclo de Educación Primaria o con un nivel de autonomía que posibilite la realización de las tareas educativas con menor dependencia del tutor, la intervención se realizará en grupos de cinco o seis alumnos.

El equipo docente de las aulas abiertas está formado, con carácter general, por un maestro especialista en pedagogía terapéutica, como tutor del grupo, al que dedica la totalidad de su horario; por un especialista en audición y lenguaje, con una dedicación horaria que está en función de las necesidades educativas del grupo de alumnos, y por un auxiliar técnico educativo o cualquier otro profesional con la debida titulación, cualificación y perfil que se considere necesario para complementar la atención a este 
alumnado. Además, el alumnado de las aulas abiertas puede recibir docencia de los especialistas en Educación Física, Música y Religión o alternativa. Estas áreas pueden impartirse en el aula abierta o junto al grupo ordinario de referencia, según la adaptación curricular de cada alumno y la organización del centro.

Asimismo, para los casos en los que se imparten los programas de formación para la transición a la vida adulta en aulas abiertas, además del maestro especialista en pedagogía terapéutica, se debe contar con un profesor técnico de servicios a la comunidad, que puede desempeñar la función tutorial.

Por otra parte, el alumnado de las aulas abiertas puede recibir apoyos educativos específicos mediante programas complementarios en cuyo desarrollo participen otras administraciones y asociaciones sin ánimo de lucro.

Los centros educativos donde se ubiquen aulas abiertas han de disponer, como requisitos mínimos para su implantación, de un mínimo de 3 alumnos, un espacio físico adecuado, con aseos y servicios higiénico-sanitarios adaptados, condiciones de accesibilidad al centro, aulas y espacios comunes, así como los profesionales antes citados.

Cada centro educativo puede tener autorizadas una o más aulas abiertas, tendiendo a establecer un número máximo de dos unidades en los centros públicos de Educación Infantil, Primaria y Secundaria y tres en los centros privados concertados donde se impartan todas las etapas educativas. Excepcionalmente y de manera justificada, el órgano competente podrá autorizar un número superior de aulas abiertas en aquellos casos que lo requieran las necesidades de escolarización del alumnado.

Además de estas aulas abiertas, existe una segunda modalidad de aulas específicas, conformada por las aulas especializadas para alumnado con TEA. Esta modalidad está recogida en la Orden de 12 de febrero de 2015 por la que se regula la organización y funcionamiento de las aulas especializadas para el alumnado con trastornos del espectro del autismo en centros educativos sostenidos con fondos públicos de la Comunidad Autónoma de Extremadura. El artículo 3 de esta orden establece que "estas aulas deben ser entendidas como un recurso del centro educativo y no exclusivamente como un espacio de escolarización. Por lo tanto, el alumnado receptor de este recurso será atendido tanto en el aula especializada como en el aula ordinaria con el grupo de referencia, así como en cualquier otro espacio del centro educativo y en otras actividades extraescolares organizadas por el centro. Por tanto, nunca pueden entenderse como un espacio de escolarización total”.

En los centros públicos, la ratio del alumnado atendido en las aulas especializadas de TEA, con carácter general, es de tres a seis alumnos y las horas de permanencia en las mismas pueden variar durante el curso según la evolución del alumnado

En relación a los profesionales que atienden estas aulas, el artículo 9 de la citada orden establece que:

Las aulas especializadas de TEA serán atendidas, con carácter general, por un maestro especialista en audición y lenguaje que coordinará el funcionamiento de estas aulas y dedicará la totalidad de su horario a la atención de las mismas; un especialista en pedagogía terapéutica, con una dedicación horaria que estará en función de las necesidades educati- 
vas del grupo de alumnos y alumnas; así como un auxiliar técnico educativo, o aquel otro profesional con la debida titulación, cualificación y perfil, para favorecer la autonomía y la integración social del alumnado. En el caso de aulas especializadas en la etapa de secundaria obligatoria, los profesionales no docentes se adscribirán al departamento de orientación del centro. En los institutos de Educación Secundaria Obligatoria, los educadores sociales llevarán a cabo funciones de apoyo a las tareas generales de estas aulas.

Los centros educativos donde se ubiquen aulas especializadas de TEA han de disponer, como requisitos mínimos para su implantación, de un mínimo de tres alumnos, espacio físico adecuado y los profesionales antes citados.

\subsection{Galicia}

En Galicia, las primeras unidades de aulas de educación especial ubicadas en centros ordinarios se crearon a finales de los setenta, junto con los primeros servicios de orientación educativa (Núñez y Salvado, 1999). La Consejería de Cultura, Educación y Ordenación Universitaria de la Junta de Galicia otorga a esta modalidad el nombre de aulas específicas de educación especial. Según el Decreto 229/2011, se definen como "el recurso más adecuado para atender las necesidades educativas especiales de determinado alumnado, facilitando la participación y la posibilidad de compartir actividades y espacios del centro ordinario que favorezcan la inclusión”. Las enseñanzas en las unidades de educación especial de los centros ordinarios contemplan una educación básica obligatoria (con una duración mínima de diez años) y una formación profesional adaptada y de transición a la vida adulta.

La edad máxima para permanecer en ellas es de diecinueve años, y la ratio que puede escolarizarse en aulas específicas es de cinco alumnos como máximo, aunque excepcionalmente la Consejería puede variar el número en función de las necesidades del alumnado que se atienda. El alumnado participa en dinámicas del aula ordinaria $\mathrm{y}$ en actividades que se realizan en el centro, de manera que se beneficia del entorno normalizado a la vez que fomentan valores de convivencia y tolerancia hacia el resto del alumnado.

Zabalza y Cid (2004) realizaron un estudio para analizar las medidas organizativas que se utilizan para dar respuesta al alumnado con necesidades educativas en los centros ordinarios de la Comunidad Autónoma de Galicia, conocer la situación de los alumnos y el tipo de escolarización en el que se encontraban. La muestra estaba compuesta por los directores de 1.725 centros, excluidos los de centros de educación especial, a los que se les administró un cuestionario descriptivo elaborado ad hoc. Entre los resultados, destaca que el tipo de escolarización que sobresale sea el del apoyo a tiempo parcial fuera del aula ordinaria para el $47 \%$ del alumnado; el apoyo a tiempo completo en un aula separada para el 24,9\%; por último, la opción de aula de educación especial en centro ordinario estaba destinada al 0,6\% del alumnado. Así, aunque el aula de educación especial se contemple para un reducido número de alumnos, casi el $30 \%$ del alumnado recibía apoyo a tiempo completo en un aula separada de su grupo natural de compañeros. 


\subsection{Madrid}

En Madrid no existe una normativa específica para las aulas de escolarización específica en centros ordinarios; sin embargo, sí se establece esta posibilidad cuando las necesidades de escolarización en la modalidad educativa de educación especial de una determinada localidad lo hacen necesario, creando aulas de educación especial en centros ordinarios. Las enseñanzas que se imparten en estas aulas son Educación Infantil Especial, para alumnos de entre tres y seis años, y Enseñanza Básica Obligatoria (ЕBO), para alumnos de entre seis y dieciséis/dieciocho años. Estas aulas se rigen por el Reglamento Orgánico del Centro en el que estén ubicadas y están obligadas a elaborar un proyecto de gestión de los recursos materiales y humanos, quedando incluido en la correspondiente programación anual.

Mención especial requieren las aulas específicas para alumnos con trastorno del espectro autista que se establece en "centros preferentes" de los que cada curso aprueba la Comunidad de Madrid. Se incluyen en ese listado tanto centros públicos como privados sostenidos con fondos públicos de Educación Primaria y Educación Secundaria.

\subsection{Murcia}

En Murcia, se denomina a las unidades especializadas en centros educativos ordinarios aulas abiertas especializadas (Decreto 359/2009). Las aulas abiertas especializadas pueden ser genéricas o específicas. En el primer caso, ofrecen al alumnado gravemente afectado los servicios especializados que precisa en centros ordinarios; en el segundo, se consideran específicas las aulas que, con la misma finalidad, escolarizan alumnado con necesidades educativas especiales derivadas de una pluridiscapacidad específica.

Las aulas abiertas especializadas, en consonancia con lo dispuesto en el artículo 3 de la Orden de 24 de mayo de 2010, tienen por objeto proporcionar un contexto adecuado para determinados alumnos y alumnas que presentan necesidades educativas especiales graves y permanentes derivadas de:

- Autismo y otros trastornos generalizados del desarrollo.

- Discapacidad psíquica severa.

- Pluridiscapacidades: discapacidad auditiva severa y profunda asociada a discapacidad psíquica; discapacidad motora grave o asociada a discapacidad psíquica, y discapacidad psíquica con alteraciones graves de comunicación.

La selección de los alumnos escolarizados en las aulas abiertas específicas se realiza después de la evaluación psicopedagógica y el dictamen de escolarización oportunos, donde se recomiende esta modalidad de escolarización como la más idónea. La escolarización de este alumnado en un aula abierta se lleva a cabo cuando requiere una atención individualizada, con adaptaciones significativas del currículo que no pueden ser atendidas en el marco del aula ordinaria o cuando se han agotado todas las medidas organizativas, metodológicas y curriculares posibles en el aula ordinaria. 
La ratio del alumnado escolarizado en un aula abierta puede oscilar entre tres y cinco, en el caso de aulas abiertas de segundo ciclo de Educación Infantil, y de cuatro a siete en las aulas abiertas de Educación Básica Obligatoria y transición a la vida adulta. En el caso de primer ciclo de Educación Infantil, el aula abierta contará con un máximo de seis alumnos.

Las aulas abiertas tienen como referencia el proyecto educativo del propio centro. Asimismo, el aula abierta debe tener las programaciones correspondientes a los tramos y etapas en los que el alumnado esté escolarizado, en las que se contemplen todas las adaptaciones significativas del currículo necesarias. Además, los alumnos cuentan con un plan de trabajo individualizado (PTI) elaborado por el equipo docente del aula abierta y que contiene las medidas organizativas que den respuesta a las necesidades de cada alumno, así como la adecuación de los elementos del currículo o las adaptaciones individuales de las áreas.

Con el objeto de favorecer al máximo la integración y la participación del alumnado en la dinámica general del centro, los centros educativos que tengan un aula abierta deben propiciar que su alumnado realice diferentes actividades con su grupo de referencia del centro, en la medida que corresponda. Asimismo, el alumnado de un aula abierta comparte tiempos y espacios comunes con el resto del alumnado del centro.

La edad máxima de permanencia en estas unidades en centros de infantil y primaria, con carácter general, es hasta los 12 años, aunque puede prolongarse de forma ordinaria hasta los dieciséis años, y con carácter extraordinario hasta los dieciocho años, autorizada por el centro directivo correspondiente.

El alumnado mayor de 12 años se escolariza en un aula abierta de un centro de Educación Secundaria. Excepcionalmente, cuando la zona no dispone de esa medida o no existen posibilidades de implantación de la misma, dichos alumnos pueden escolarizarse en un aula abierta de un centro de Educación Primaria. De forma general, en las aulas abiertas implantadas en centros de Educación Secundaria, se imparten las enseñanzas de los cuatro últimos cursos de la Educación Secundaria Obligatoria, organizando las materias por ámbitos e incluyendo una asignatura de libre configuración, “Competencias y aprendizajes funcionales para la vida”. La edad máxima de permanencia en dichas aulas es de dieciocho años, pudiendo prolongarse de forma extraordinaria hasta los diecinueve años.

Las aulas abiertas cuentan, con carácter general, con un equipo docente formado por un maestro especialista en pedagogía terapéutica, tutor del grupo, un especialista en audición y lenguaje y un auxiliar técnico educativo. Además, el alumnado de las aulas abiertas puede recibir apoyos educativos específicos mediante programas complementarios en cuyo desarrollo participen otras administraciones y asociaciones sin ánimo de lucro. Dichos programas han de estar incluidos en la planificación efectuada por el jefe de estudios para el aula abierta y debidamente coordinados con el equipo docente del aula.

Por otra parte, en el caso de aula abierta para alumnos sordos o con discapacidad auditiva, el tutor debe ser un maestro con especialidad en audición y lenguaje o en pedagogía terapéutica con conocimientos amplios en lengua de signos española, convenientemente acreditados. Asimismo, las aulas abiertas en centros educativos donde 
se imparten los programas de formación para la transición a la vida adulta, además del maestro especialista en pedagogía terapéutica, deben contar con un profesor técnico de formación profesional que puede desempeñar la función tutorial.

El horario lectivo del alumnado de las aulas abiertas es, con carácter general, de veinticinco horas semanales y se potencia que los alumnos participen, de forma individual o en grupo, en las actividades y materias del centro, sesiones de educación artística, música, educación física y psicomotricidad, actividades extraescolares, etc.

Los centros donde se ubican aulas abiertas disponen, como requisitos mínimos para su implantación, de un mínimo de cuatro alumnos; espacio físico adecuado de, al menos, treinta metros cuadrados; aseos adaptados, y accesibilidad al centro, aula y demás espacios comunes, además de los profesionales antes citados.

\subsection{Navarra}

En Navarra, el Departamento de Educación del Gobierno Autonómico nombra a estas aulas unidades de transición o unidades de currículo especial que, según la Orden 93/2008 por la que se regula la atención a la diversidad, son unidades que proporcionan un ambiente altamente estructurado y organizado, al mismo tiempo que permiten al alumnado beneficiarse de las posibilidades integradoras y normalizadoras de un contexto ordinario.

La Comunidad Foral de Navarra comenzó a escolarizar al alumnado con discapacidad intelectual en Secundaria durante el curso 1995-1996, año en el que la legislación incluyó, entre otras alternativas, la modalidad de aula de educación especial en centros ordinarios a las que se les confiere cierta flexibilidad, donde el alumnado participa también en las actividades del centro y en determinadas áreas en un aula ordinaria (Alonso, 2011).

Las unidades de currículo especial atienden a un pequeño grupo de alumnos, cuya ratio ronda entre tres y siete estudiantes, que durante la etapa de secundaria pueden estar escolarizados hasta los veintiún años. El objetivo, según Lizasoain (2012), es dotar de instalaciones que permitan la participación en determinadas actividades con el resto del alumnado, a la vez que puedan recibir una enseñanza adaptada en un aula específica destinada a la autonomía, el tránsito a la vida adulta y las habilidades pre-laborales.

El marco legislativo da instrucciones para la escolarización en unidades de currículo especial al alumnado con discapacidad intelectual con déficit intelectual ligero o medio, por lo que el cociente intelectual es el factor que prima para determinar la modalidad. Esto deja en segundo plano la responsabilidad de los centros escolares para ofrecer las adaptaciones necesarias para poder responder a la diversidad del alumnado (Aparicio, 2007).

En la Comunidad de Navarra, además de las unidades de currículo especial, existe otra modalidad similar denominada aula alternativa a centro de educación especial en zona rural, insertada en centros ordinarios, cuyo objetivo es acercar estas unidades a 
zonas rurales alejadas de centros de educación especial con la finalidad de evitar largos desplazamientos y acercar los recursos al entorno de los beneficiarios (Elcarte, 2002).

\subsection{País Vasco}

En el País Vasco, el Departamento de Educación, Política Lingüística y Cultura denomina a esta modalidad de escolarización aulas estables (Decreto 118/1998), con las que se pretende atender al alumnado con discapacidades psíquicas graves y permanentes que exigen una ayuda constante e individualizada y un currículo adaptado no compatible con el currículo ordinario, dentro del centro ordinario, en aulas dotadas de medios materiales y humanos que puedan responder a sus necesidades especificas, sin perjuicio de su integración en la dinámica general del centro. Por tanto, están destinadas al alumnado cuya escolarización requiere una atención individualizada y un currículo diferenciado, fundamentalmente en Secundaria, con el objetivo de llevar a cabo un proceso de tránsito a la vida adulta. De esta forma, el alumnado con necesidades educativas especiales derivadas de una discapacidad, que ha cumplido dieciséis años y que a juicio del equipo educativo no puede obtener el título de Graduado en Educación Secundaria, puede acceder a una formación adaptada que le capacite para su incorporación al mundo del trabajo. Esta formación adaptada puede extenderse hasta los veinte años.

El número de alumnos por aula es de cuatro o cinco en razón a su problemática, necesitando una dotación de material y equipamiento para desarrollar el currículo específico del grupo. Además de profesorado específico de educación especial con las especializaciones de pedagogía terapéutica y audición y lenguaje, el Departamento de Educación, Universidades e Investigación debe disponer en número suficiente de profesionales para el apoyo del alumnado con necesidades educativas especiales.

Para Martínez (2000), el término "estable" en la denominación de estas aulas se basa en dos motivos:

- La asignación de recursos estables en función de las necesidades educativas del alumnado: un tutor, un auxiliar de aula o el material y equipamiento específico, entre otros.

- Ser un referente para los estudiantes escolarizados en esta modalidad que comparte espacios comunes, horarios y otras actividades con el centro ordinario en que está situada.

Surgen en 1982, a partir del Plan de Educación Especial del Gobierno Vasco, como una alternativa educativa al alumnado de educación especial para acceder a centros públicos ordinarios a través de un soporte de aulas de educación especial, con el objetivo de ser un elemento integrador, intentando que su alumnado estuviese el menor tiempo posible en ellas para no terminar originando una segregación (Orcasitas, 2003). El alumnado debe estar escolarizado preferentemente en el aula ordinaria, adecuando recursos, metodología y llevando a cabo adaptaciones curriculares, de manera que se limite la alternativa del aula estable como última opción (Vega y Garín, 2012). 


\section{Conclusiones}

Como se ha podido comprobar, las diferentes comunidades autónomas ofrecen alternativas que difieren en aspectos importantes como:

- La consideración de estas aulas como unidades que sustituyen a los centros de educación especial, pero que cumplen las mismas funciones: en este caso estarían Asturias, Cantabria, Castilla y León y La Rioja, donde no existe una normativa específica que regule estas aulas. También serían similares las aulas creadas en las comunidades de Andalucía, Aragón, Baleares y Galicia, pero en estos casos sí hay normativas específicas sobre su regulación.

- La coexistencia de aulas sustitutorias a los centros de educación especial en los centros ordinarios, acompañadas de la creación de aulas específicas para alumnado con trastorno del espectro autista (TEA): Castilla-La Mancha y Madrid (en centros preferentes); o para alumnado con trastornos del lenguaje o trastornos generales de desarrollo: Comunidad Valenciana.

- O bien la consideración de aulas especializadas que tienen como objetivo que el alumnado con necesidades especiales graves se beneficie de su escolarización en un centro ordinario, fomentando su inclusión en la mayor medida posible: Canarias, Extremadura, Murcia, Navarra y País Vasco.

La Tabla 1 muestra las diferentes denominaciones que se establecen para estas aulas y que ya explicitan algunas diferencias en su consideración:

\section{TABLA 1. Diferentes denominaciones, diferentes consideraciones}

\begin{tabular}{|c|c|}
\hline Denominación & Comunidades autónomas \\
\hline $\begin{array}{l}\text { Aulas Específicas de Educación Especial en centros ordinarios } \\
\text { Unidades de Educación Especial en centros ordinarios } \\
\text { Unidades de Educación Especial }\end{array}$ & $\begin{array}{l}\text { ANDALUCÍA } \\
\text { ARAGÓN } \\
\text { ASTURIAS } \\
\text { CANTABRIA } \\
\text { CASTILLA Y LEÓN } \\
\text { CASTILLA-LA MANCHA } \\
\text { CATALUÑA } \\
\text { COMUNIDAD VALENCIANA } \\
\text { GALICIA } \\
\text { LA RIOJA } \\
\text { MADRID }\end{array}$ \\
\hline $\begin{array}{l}\text { Aulas abiertas especializadas para alumnado con trastornos } \\
\text { del Espectro del Autismo } \\
\text { Aulas especializadas para alumnos con TEA } \\
\text { Aulas TEA en centros preferente }\end{array}$ & $\begin{array}{l}\text { CASTILLA-LA MANCHA } \\
\text { MADRID }\end{array}$ \\
\hline $\begin{array}{l}\text { Unidad educativa con currículo propio } \\
\text { Aulas Enclave } \\
\text { Aulas abiertas especializadas generales y específicas } \\
\text { Unidades de transición } \\
\text { Aulas estables }\end{array}$ & $\begin{array}{l}\text { BALEARES } \\
\text { CANARIAS } \\
\text { EXTREMADURA } \\
\text { MURCIA } \\
\text { NAVARRA } \\
\text { PAÍS VASCO }\end{array}$ \\
\hline
\end{tabular}


A partir de estas consideraciones se pueden comprobar diferencias en relación a las características del alumnado al que va dirigida la modalidad; las ratios que se ofrecen que, en algunos casos, varían según las necesidades del alumnado; la edad máxima de escolarización; los requisitos para implementarlas en los centros ordinarios, o el equipo de profesionales que en ellas intervienen. En la Tabla 2 podemos visualizar las diferencias en relación al alumnado que acogen y la ratio prevista y que se agrupan en tres grandes categorías: incluyen a alumnos en función de necesidades que no pueden atenderse en aulas ordinarias, haciendo referencia a la necesidad de adaptaciones curriculares significativas extremas o en función de las discapacidades que presentan.

\begin{tabular}{|c|c|c|}
\hline Alumnado & $\begin{array}{l}\text { Comunidades } \\
\text { autónomas }\end{array}$ & Ratio \\
\hline $\begin{array}{l}\text { Alumnado con necesidades específicas graves, } \\
\text { que no pueden ser atendidos mediante las } \\
\text { medidas de atención a la diversidad en los } \\
\text { centros ordinarios }\end{array}$ & $\begin{array}{l}\text { ASTURIAS, } \\
\text { CANTABRIA, LA } \\
\text { RIOJA, CASTILLA } \\
\text { Y LEÓN }\end{array}$ & No se establece \\
\hline $\begin{array}{l}\text { Alumnado con necesidades educativas } \\
\text { especiales que no puede ser atendido en aulas } \\
\text { ordinarias y no existen centros de educación } \\
\text { especial }\end{array}$ & CATALUÑA & De 3 a 8 alumnos \\
\hline $\begin{array}{l}\text { Alumnado que, por la gravedad o permanencia } \\
\text { de sus necesidades educativas, requiera recursos } \\
\text { y atenciones que no puedan proporcionarse en } \\
\text { contextos ordinarios }\end{array}$ & GALICIA & $\begin{array}{l}5 \text { alumnos como } \\
\text { máximo, aunque } \\
\text { excepcionalmente } \\
\text { podría variar en } \\
\text { función de las } \\
\text { necesidades del } \\
\text { alumnado }\end{array}$ \\
\hline $\begin{array}{l}\text { Alumnado con condiciones personales de } \\
\text { discapacidad, que requiera adaptaciones } \\
\text { significativas y en grado extremo en las áreas } \\
\text { del currículo oficial que les corresponda por su } \\
\text { edad. }\end{array}$ & ANDALUCÍA & $\begin{array}{l}\text { De } 3 \text { a } 5 \text { para TGD, de } \\
6 \text { a } 8 \text { para personas } \\
\text { con discapacidad } \\
\text { sensorial o de } 8 \text { a } 10 \\
\text { para personas con } \\
\text { movilidad reducida }\end{array}$ \\
\hline $\begin{array}{l}\text { Alumnado con discapacidad intelectual } \\
\text { moderada con o sin trastorno de personalidad, } \\
\text { a TGD, a discapacidad motriz severa o a } \\
\text { plurideficiencias, que necesita apoyos y } \\
\text { adaptaciones curriculares significativas }\end{array}$ & BALEARES & $\begin{array}{l}\text { Hasta } 7 \text { alumnos, la } \\
\text { ratio puede disminuir } \\
\text { si alguno de sus } \\
\text { integrantes tiene una } \\
\text { necesidad de apoyo } \\
\text { generalizado }\end{array}$ \\
\hline
\end{tabular}




\section{TABLA 2. Características y ratio del alumnado escolarizado (cont.)}

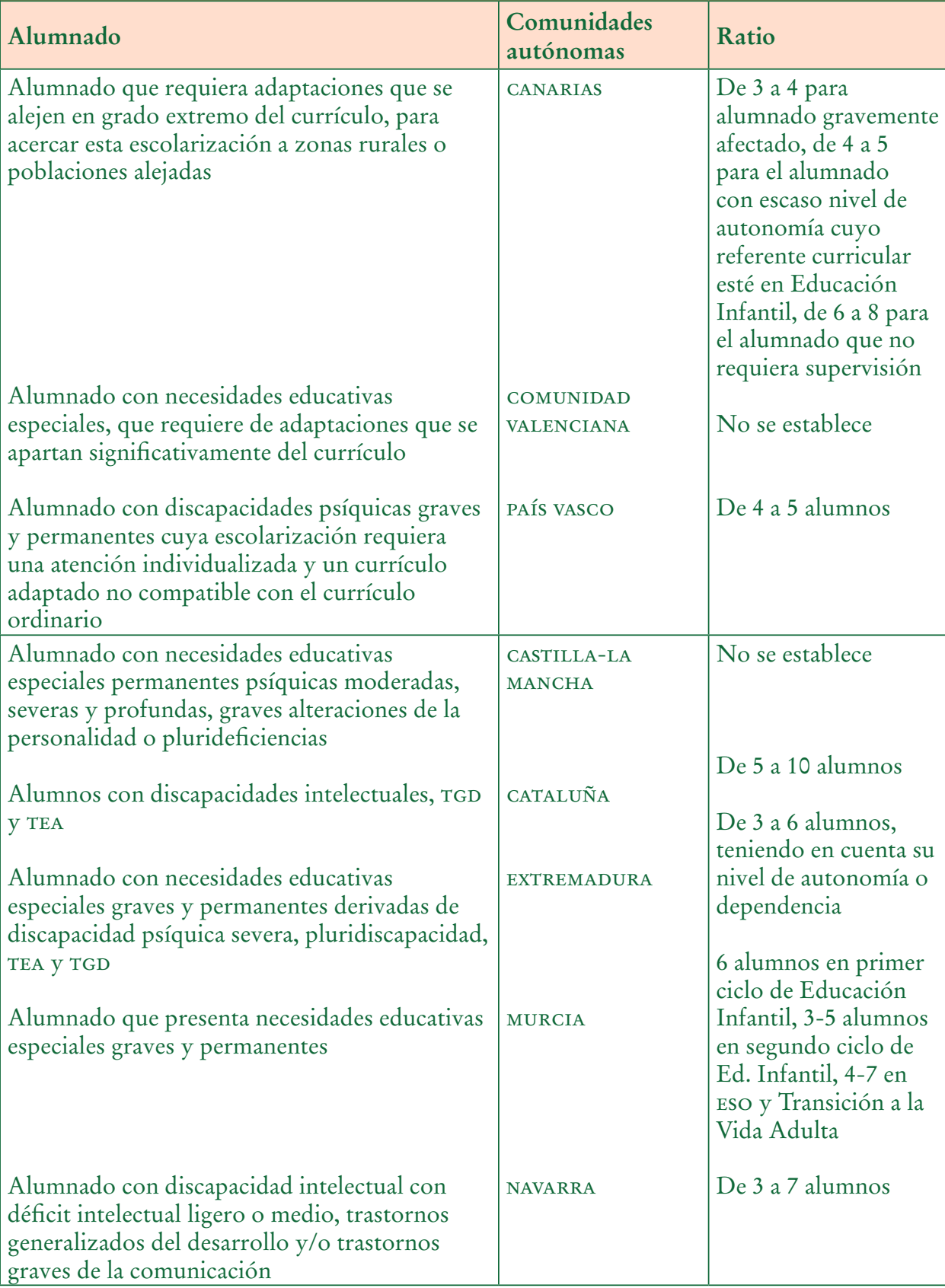

(C) Ediciones Universidad de Salamanca / CC BY-NC-ND

Siglo Cero, vol. 50 (3), n. ${ }^{\circ}$ 271, 2019, julio-septiembre, pp. 89-120 


\section{TABLA 2. Características y ratio del alumnado escolarizado (cont.)}

\begin{tabular}{|l|l|l|}
\hline Alumnado & $\begin{array}{l}\text { Comunidades } \\
\text { autónomas }\end{array}$ & Ratio \\
\hline $\begin{array}{l}\text { En Ed. Primaria: alumnos afectados de TGD } \\
\text { que no lleven asociada una deficiencia mental y } \\
\text { alumnos con trastornos muy graves por déficit } \\
\text { de atención y comportamiento perturbador }\end{array}$ & ARAGóN & No se establece \\
\hline
\end{tabular}

En cuanto a la edad máxima de permanencia en estas aulas, aunque la escolarización obligatoria finaliza a los dieciséis años de edad, son muchas las comunidades que plantean la posibilidad de seguir ofreciendo el recurso de manera que se prorrogue la estancia de estos alumnos en el centro ordinario (Tabla 3).

\begin{tabular}{|l|l|}
\hline \multicolumn{2}{|c|}{ TABLA 3. Edad máxima de permanencia en aulas de educación especial } \\
en centros ordinarios
\end{tabular}

Sobre los profesionales que constituyen el cuerpo docente de estas aulas, no se especifican en muchas de las comunidades autónomas, pero las que hacen alusión explícita a este personal, incluyen siempre a un maestro especialista en educación especial o pedagogía terapéutica, un auxiliar técnico educativo (o profesional con cualificación equivalente) y, en la mayoría de los casos, un maestro especialista en audición y lenguaje. En algunas comunidades (Extremadura y Murcia) se considera también la necesidad de un profesor técnico de servicios a la comunidad para las aulas en las que se impartan programas formativos de transición a la vida adulta (Tabla 4). 


\section{Tabla 4. Profesionales adscritos a estas aulas}

\section{Profesionales}

Maestro de educación especial o PT y un auxiliar técnico

Educativo

Profesor de apoyo a las necesidades específicas de apoyo educativo, auxiliar educativo y maestro de taller (si corresponde)

2 psicopedagogos y un educador social

Comunidades autónomas

BALEARES / CANARIAS

Maestro especialista en PT, especialista en AL y un ATE. Especialistas en Ed. Física, Música y Religión o alternativa

En centros donde se impartan los programas de formación para la transición a la vida adulta, también un PTSC

Maestro especialista en PT, especialista en AL y un ATE. Pueden recibir apoyo de personal de otras administraciones y asociaciones sin ánimo de lucro

En aquellas donde se impartan los programas de formación para la transición a la vida adulta: maestro PT y un profesor técnico de formación profesional

Profesorado específico de educación especial con las especializaciones de PT y AL, profesionales para el apoyo del alumnado con necesidades educativas especiales

No se especifican
MURCIA

CATALUÑA

EXTREMADURA

PAÍS VASCO

Menos aún son las normativas autonómicas que recogen los requisitos que deben cumplir los centros educativos para contar con estas aulas, entre los que se encuentran: número mínimo de alumnos, profesionales necesarios para su escolarización, espacios y servicios adecuados para la enseñanza a este alumnado (Tabla 5).

\section{TABla 5. Requisitos mínimos de los centros}

\begin{tabular}{|c|c|}
\hline Requisitos & $\begin{array}{l}\text { Comunidades } \\
\text { autónomas }\end{array}$ \\
\hline $\begin{array}{l}\text { - Mínimo de 3-4 alumnos destinatarios de esta medida en la zona } \\
\text { - Los profesionales antes citados } \\
\text { - Espacio físico adecuado } \\
\text { - Aseos y servicios higiénicos-sanitarios adaptados } \\
\text { - Condiciones de accesibilidad al centro, aula y demás espacios } \\
\text { comunes }\end{array}$ & $\begin{array}{l}\text { EXTREMADURA / } \\
\text { MURCIA }\end{array}$ \\
\hline
\end{tabular}


En definitiva, las aulas especializadas persiguen:

- Favorecer una respuesta educativa en contextos más normalizados a alumnado con necesidades educativas especiales graves y permanentes.

- Mejorar la respuesta educativa a los alumnos que requieren de apoyos continuados.

- Promover experiencias de atención a la diversidad en contextos lo menos restrictivos posible.

- Ofrecer mejor respuesta a las necesidades educativas de alumnos con TEA y/o patologías afines, así como pluridiscapacidades en centros ordinarios.

- Fomentar actitudes de respeto y atención a la diversidad en toda la comunidad educativa y sociedad en general.

Tal y como indican Capel, Jiménez, Martínez y Escobar (2003: 3):

Las aulas abiertas especializadas (AAE) no son aulas cerradas o minicentros, sino que forman parte a todos los efectos del centro ordinario y el alumnado escolarizado en ellas comparten con el resto de alumnos y alumnas diferentes espacios y situaciones interactivas, así como determinadas áreas curriculares. Por otra parte, las AAE no deben utilizarse para escolarizar alumnos y alumnas del centro ordinario con otras necesidades educativas especiales no tan graves ni permanentes, cuya modalidad de escolarización idónea es la integración.

Podemos concluir expresando que las diversas aulas de educación especial en centros ordinarios tienen una tendencia hacia la inclusión, aunque las normativas de las diferentes comunidades autónomas no siempre se ajustan a este propósito.

\section{Referencias bibliográficas}

Alemán, D. (2008). Estudio sobre las ventajas e inconvenientes que presentan las aulas enclave en relación con los centros específicos. Recuperado en http://hdl.handle.net/10 553/3174Allodi.

Alonso, P. (2011). U.c.e. Unidad de currículo especial. Revista Arista Digital, 5, 399-406.

Aparicio, M. (2007). La educación como elemento estructural del tránsito a la vida adulta de los jóvenes en situación de discapacidad. EMIGRA Working Papers, 79. Recuperado en www. emigra.org.es.

Auyanet, A., Pérez, M., Vega, R., Rodríguez, C., Pulido, F. y Rivero, S. (2004). Aulas enclave en la provincia de Las Palmas. XII Congreso Aetapi, "Alcanzando Metas”. Las Palmas de Gran Canaria, 11, 12 y 13 de noviembre de 2004.

Bellver, M., Diez, M., López, M. y Navarro, A. (2009). La programación didáctica en un aula CyL: La experiencia del CEIP "El Parque" de la Cañada (Paterna). xix Congreso Nacional de la Federación Española de Asociaciones de Profesores de Audición y Lenguaje. Valencia, 25 al 27 de junio de 2009.

Capel, M. D., Jiménez, P., Martínez, C. y Escobar, M. A. (2003). Aula Abierta Específica de Alumnos con Trastorno del Espectro Autista. En I Jornadas de Comunicación Aumentativa y Alternativa. Consejería de Educación y Cultura. Servicio de Atención a la Diversidad. Septiembre 2003. Recuperado en: http://www.jmunozy.org/files/9/Necesidades_Educativas_Especificas/aula_pt/documentos/aula_abierta_especIfica.pdf. 
Elcarte, M. (2002). Atención a las necesidades educativas especiales en la Comunidad Foral de Navarra. En I Congreso Regional Las Necesidades Educativas Especiales: Situación actual y retos de futuro. Navarra.

Gónzalez, J. y Cámara, M. (2006). Programa de tránsito a la vida adulta en la comunidad autónoma de Canarias. Las Palmas: Consejería de Educación, Cultura y Deportes del Gobierno de Canarias.

Lizasoain, O. (2012). Formación profesional para personas con discapacidad cognitiva en Espana: del colegio al mundo laboral. Recuperado en http://www.descubreme.cl/wp-content/ uploads/2012/05/Formaci\% C3\%B3n-profesional-para-personas-con-capacidad-cognitiva-en-Espa\%C3\%B1a-Olga-Lizasoain.pdf.

Lledó A., Fernández M. y Grau, S. (2006). La detección y atención educativa en los trastornos generalizados del desarrollo: autismo y sindrome de Asperger. Alicante: San Vicente.

MARTínez, A. (2000). Las aulas estables para alumnado con necesidad de apoyos generalizados en centros de ESO: orientaciones para su funcionamiento. Vitoria-Gasteiz: Servicio Central de Publicaciones del Gobierno Vasco.

Merino, M. (2008). El proceso de escolarización para el alumnado con necesidades educativas especiales. Revista Digital Enfoques Educativos, 24, 91-102.

Morueco, M., Massanet, A., Gómez, R., Martínez, M., Florit, J., Forteza, A., Noguera, A., Roca, I., Mora, C., Roso, S., Martínez, L. y Gómez, E. (2008). Apoyos itinerantes para el alumnado con Autismo en Baleares: las UVAIS como Unidades de Apoyo. xiv Congreso Nacional de Autismo-AETAPI. "Comprometidos con el futuro". 12, 13, 14 y 15 de noviembre de, San Sebastián y Bilbao.

NúÑez, T. y Salvado, M. (1999). La intervención psicopedagógica en Galicia. Infancia y Aprendizaje, 87, 89-105.

Orcasitas, J. (2003). 20 años de integración escolar en el País Vasco: haciendo historia, construyendo un sistema educativo de calidad para todos. En Actas del Congreso Guztientzako Eskola La respuesta a las necesidades educativas especiales en la escuela vasca inclusiva. Donostia. País Vasco.

Pérez, L., Guillén, A., Pérez, M., Jiménez, I. y Bonilla, M. (2008). La atención educativa al alumnado con trastorno del espectro autista. Sevilla: Consejería de Educación.

Ramírez, C. (2010). ¿Cómo se organiza la enseñanza en un centro específico o aula específica de educación especial? Temas para la Educación: Revista Digital para Profesionales de la Enseñanza, 8. Recuperado en http://www 2.fe.ccoo.es/andalucia/docu/p5sd7182.pdf.

Ruiz, E. (2007). Integración educativa en el aula ordinaria con apoyos de los alumnos con síndrome de Down. Revista Sindrome de Down, 24, 2-13.

VEgA, A. y Garín, S. (2012). Nuevos maestros y maestras para una eficaz educación inclusiva. Indivisa: Boletín de Estudios e Investigación, 13, 104-120.

ZabalzA, M. y Cid, A. (2004). Integración escolar: aspectos organizativos para la atención a los alumnos con necesidades educativas especiales en la Comunidad Autónoma de Galicia vistos por los directores de centros escolares. Enseñanza, 22, 237-261.

\section{Legislación consultada}

\section{Nacional}

- Constitución española (1978). BOE n. ${ }^{\circ}$ 311, de 29 de diciembre de 1978.

- Orden de 18 de septiembre de 1990, por la que se establecen las proporciones de profesionales/alumnos en la atención educativa de los alumnos con necesidades especiales. 
- Orden de 22 de julio de 1999, por la que se regulan las actuaciones de compensación educativa en centros docentes sostenidos con fondos públicos.

- Real Decreto 696/1995, de 28 de abril, de ordenación de la educación de los alumnos con necesidades educativas especiales.

- Real Decreto 299/1996, de 28 de febrero, de ordenación de las acciones dirigidas a la compensación de desigualdades en educación.

- Ley Orgánica 1/1990, de 3 de octubre, de Ordenación General del Sistema Educativo. BOE, n. ${ }^{\circ} 238,4$ de octubre de 1990, 28927-28942.

- Ley Orgánica 9/1995, de Ordenación General del Sistema Educativo.

- Ley Orgánica 10/2002, de 23 de diciembre, de Calidad de la Educación.

- Ley 51/2003, de 2 de diciembre, de igualdad de oportunidades, no discriminación y accesibilidad universal de las personas con discapacidad.

- Ley Orgánica 2/2006, de 3 de mayo, de educación. BOE, n. ${ }^{\circ}$ 106, 4 de mayo de 2006, 17158-17207.

- Ley Orgánica 8/2013, de 9 de diciembre, para la mejora de la calidad educativa. $B O E$ núm. 295, de 10 de diciembre de 2013, 97858. Gobierno de España.

\section{Andalucía}

- Orden de 13 de julio de 1994, por la que se regula el procedimiento de diseño, desarrollo y aplicación de adaptaciones curriculares en los centros docentes de Educación Infantil, Primaria y Secundaria de la Comunidad Autónoma de Andalucía.

- Decreto 213/1995, de 12 de septiembre, por el que se regulan los equipos de orientación educativa, que les encomienda un conjunto de funciones relativas al apoyo a la función tutorial del profesorado, la orientación vocacional y profesional, la atención a las necesidades educativas especiales y la compensación educativa.

- Orden de 9 de septiembre de 1997, por la que se regulan determinados aspectos de la organización y el funcionamiento de las escuelas públicas de Educación Infantil y de los colegios públicos de Educación Primaria de la Comunidad Autónoma de Andalucía.

- Instrucciones de 20 de septiembre de 1998, de las Direcciones Generales de Planificación y Ordenación Educativa y de Formación Profesional y Solidaridad en la Educación, sobre la organización de la atención educativa del alumnado con necesidades educativas especiales, por razón de discapacidad, en los institutos de Educación Secundaria autorizados para la integración.

- Orden de 16 de febrero de 1999, sobre escolarización y matriculación de alumnos y alumnas en los centros docentes públicos y privados concertados, a excepción de los universitarios.

- Instrucciones, de 9 de marzo de 1999, de la Viceconsejería de Educación y Ciencia, sobre la planificación de la escolarización en los centros docentes públicos y privados concertados, no universitarios, para el curso académico 1999/2000.

- Decreto 147/2002, de 14 de mayo, por el que se establece la ordenación de la atención educativa a los alumnos y alumnas con necesidades educativas 
especiales asociadas a sus capacidades personales. Boletín Oficial de la Junta de Andalucía, n. ${ }^{\circ}$ 58. España.

Aragón

- Decreto 217/2000, de 19 de diciembre, del Gobierno de Aragón, de atención al alumnado con necesidades educativas especiales.

- Orden de 25 de junio de 2001, del Departamento de Educación y Ciencia, por la que se regula la acción educativa para el alumnado que presenta necesidades educativas especiales derivadas de condiciones personales de discapacidad física, psíquica o sensorial o como consecuencia de una sobredotación intelectual.

- Orden de 25 de junio de 2001, del Departamento de Educación y Ciencia, por la que se establecen medidas de Intervención Educativa para el alumnado con necesidades educativas especiales que se encuentre en situaciones personales sociales o culturales desfavorecidas o que manifieste dificultades graves de adaptación escolar.

- Resolución de 3 de septiembre de 2001, de la Dirección General de Renovación Pedagógica, por la que se dictan instrucciones sobre las unidades específicas en centros de educación infantil y primaria para la atención educativa a alumnos con necesidades educativas especiales.

- Instrucciones de la Dirección General de Renovación Pedagógica, para concretar la oferta educativa ordinaria o específica, de los alumnos con necesidades educativas (27 de agosto de 2001).

- Orden de 30 de julio de 2014, de la Consejería de Educación, Universidad, Cultura y Deporte, por la que se regulan las medidas de intervención educativa para favorecer el éxito y la excelencia de todos los alumnos de la Comunidad Autónoma de Aragón desde un enfoque inclusivo.

\section{Asturias}

- Orden de 14 de febrero de 1996, por la que se regula el procedimiento para la realización de la evaluación psicopedagógica y el dictamen de escolarización y se establecen los criterios para la escolarización de los alumnos con necesidades educativas especiales.

- Resolución de 25 de abril de 1996, de la Secretaría de Estado de Educación, por la que se regula la elaboración del proyecto curricular de la Enseñanza Básica Obligatoria en los centros de educación especial.

- Resolución de 29 de abril de 1996, de la Secretaría de Estado de Educación, por la que se determinan los procedimientos a seguir para orientar la respuesta educativa a los alumnos con necesidades educativas especiales asociadas a condiciones personales de sobredotación intelectual.

\section{Baleares}

- Orden de la Consejería de Educación y Cultura, de 29 de enero de 2009, por la cual se regula la creación y el funcionamiento de las unidades educativas con currículum propio. 


\section{Canarias}

- Decreto 23/1995, de 24 de febrero, por el que se regula la orientación educativa en la Comunidad Autónoma Canaria.

- Decreto 286/1995, de 22 de septiembre, de ordenación de atención al alumnado con necesidades educativas especiales.

- Orden de 24 de septiembre de 2002, por la que se establece el Sistema de Indicadores de la Educación para la Comunidad Autónoma de Canarias.

- Decreto 104/2010, de 29 de julio, por el que se regula la atención a la diversidad del alumnado en el ámbito de la enseñanza no universitaria de Canarias. Boletín Oficial de Canarias, n. ${ }^{\circ}$ 154. España

- Resolución de 9 de febrero de 2011, por la que se dictan instrucciones sobre los procedimientos y los plazos para la atención educativa del alumnado con necesidades específicas de apoyo educativo en los centros escolares de la Comunidad Autónoma de Canarias.

\section{Cantabria}

- Orden EDu/13/2005, de regulación de las bases del procedimiento de admisión del alumnado.

\section{Castilla-La Mancha}

- Decreto 138/2002, de 8-10-2002, por el que se ordena la respuesta educativa a la diversidad del alumnado en la Comunidad Autónoma de Castilla-La Mancha.

- Resolución de 18 de octubre de 2004 sobre escolarización en Centros Específicos de Educación Especial y Centros de Infantil y Primaria o Institutos de Secundaria.

- Orden de 16/01/2014, de la Consejería de Educación, Cultura y Deportes, por la que se crean, regula y ordena el funcionamiento de las Aulas Abiertas Especializadas, para el alumnado con trastorno de espectro autista, en centros públicos de la Comunidad Autónoma de Castilla-La Mancha.

\section{Castilla y León}

- Orden 1103/2003, de 28 de agosto, que lo desarrolla, atribuye al Servicio de Atención a la Diversidad el establecimiento de criterios y directrices de la orientación educativa.

- Orden Pat/920/2004, de 4 de junio, por la que se aprueba la Carta de Servicios al Ciudadano de los centros públicos de Educación Infantil y Primaria.

\section{Cataluña}

- Decreto 299/1997, de 25 de noviembre, sobre la atención educativa al alumnado con necesidades educativas especiales

- Decreto 252/2004, d'1 d'abril, pel qual s'estableix el procediment d'admissió de l'alumnat als centres docents en els ensenyaments sufragats amb fons públics. 
- Instruccions de 7 d'abril de 2005, de la Direcció General d'Ordenació i Innovació Educativa per als equips d'assessorament i orientació psicopedagògica (EAP) respecte a l'elaboració del dictàmens d'escolarització d'alumnat amb necessitats educatives especials o d'informes d'alumnat amb necessitats educatives específiques vinculades a situacions socioeconòmiques o socioculturals desfavorides.

- Resolución de 12 de enero de 2009, de la Dirección General de Cooperación Territorial, por la que se publica el Convenio de colaboración entre el Ministerio de Educación, Política Social y Deporte y la Comunidad Autónoma de Cataluña, para el Plan de apoyo a la implantación de la LOE, año 2008.

\section{Extremadura}

- Orden de 6 de julio de 2012 por la que se crean aulas abiertas especializadas de Educación Especial en centros ordinarios de la Comunidad Autónoma de Extremadura y se regula su organización y funcionamiento.

- Orden de 12 de febrero de 2015 por la que se regulan la organización y funcionamiento de las aulas especializadas para el alumnado con trastornos del espectro del autismo en centros educativos sostenidos con fondos públicos de la Comunidad Autónoma de Extremadura.

\section{Galicia}

- Decreto 320/1996, del 26 de julio, de ordenación de la educación de alumnos e alumnas con necesidades educativas especiales.

- Decreto 120/1998, del 23 de abril, por el que se regula la orientación educativa y profesional en la Comunidad Autónoma de Galicia.

- Orden del 24 de julio de 1998 por la que se establece la organización y funcionamiento de la orientación educativa y profesional de la Comunidad Autónoma de Galicia.

- Orden del 27 de diciembre de 2002 por la que se establecen las condiciones y criterios para la escolarización en centros sostenidos con fondos públicos del alumnado de enseñanzas no universitarias con necesidades educativas especiales.

- Decreto 229/2011, de 7 de diciembre, por el que se regula la atención a la diversidad del alumnado de los centros docentes de la Comunidad Autónoma de Galicia. Diario Oficial de Galicia, n. ${ }^{\circ}$ 242. España.

\section{La Rioja}

- Decreto 21/2004, de 18 de marzo, sobre elección de centro, criterios de admisión de alumnos en centros no universitarios sostenidos con fondos públicos y acceso a determinadas enseñanzas.

\section{Madrid}

- Orden 70/2005, de 11 de enero, del Consejero de Educación de la Comunidad de Madrid, por la que se regula con carácter excepcional la flexibilización de la 
duración de las diferentes enseñanzas escolares para los alumnos con necesidades educativas específicas por superdotación intelectual.

- Circular de la Dirección General de Centros Docentes relativa al funcionamiento de los equipos de orientación educativa y psicopedagógica para el curso 2004/2005 (30 de julio de 2004).

- Circular de la Dirección General de Centros Docentes relativa a la organización en los centros públicos de Educación Infantil y Primaria y Educación Secundaria, del profesorado de apoyo educativo al alumnado con necesidades educativas especiales asociadas a condiciones personales de discapacidad.

- Orden 1250/2000, de 25 de abril, de la Consejería de Educación, por la que se establece la sectorización de los equipos de orientación educativa y psicopedagógica.

- Resolución de 29 de abril de 1996, de la Dirección General de Centros Escolares, sobre organización de los Departamentos de Orientación en Institutos de Educación Secundaria.

\section{Murcia}

- Orden de 6 de mayo de 2002, de la Consejería de Educación y Cultura, por la que se crea el equipo de orientación educativa y psicopedagógica específico de convivencia escolar, dependiente de la Dirección General de Formación Profesional, Innovación y Atención a la Diversidad.

- Decreto 359/2009, de 30 de octubre, por el que se establece y regula la respuesta educativa a la diversidad del alumnado en la Comunidad Autónoma de la Región de Murcia. Diario Oficial de la Región de Murcia, n..$^{\circ} 254$. España.

- Orden de 24 de mayo de 2010, de la Consejería de Educación, Formación y Empleo, por la que se regulan la autorización y el funcionamiento de las aulas abiertas especializadas en centros ordinarios públicos y privados concertados de la Comunidad Autónoma de la Región de Murcia.

\section{Navarra}

- Decreto Foral 56/1994, de 28 de febrero, por el que se regula la admisión del alumnado en centros de enseñanzas no universitarias de la Comunidad Foral de Navarra sostenidos con fondos públicos.

- Orden Foral 133/1998, de 8 de mayo, por la que se dan instrucciones para la escolarización y atención educativa del alumnado con necesidades educativas especiales asociadas a discapacidad psíquica, sensorial y motórica en centros ordinarios de Secundaria para continuar la Enseñanza Básica.

- Decreto Foral 153/1999, de 10 de mayo, por el que se regula la orientación educativa en los centros públicos.

- Orden Foral 39/2001 de 20 de febrero, sobre el procedimiento para la escolarización del alumnado con necesidades educativas especiales asociadas a discapacidad psíquica, motórica y sensorial.

- Orden Foral 31/2001, de 29 de febrero, sobre el procedimiento de escolarización del alumnado con necesidades educativas especiales. 
País Vasco

- Decreto 206/1992, de 21 de julio, modificación de los derechos por los que se regulan la creación y el funcionamiento de los centros de orientación pedagógica.

- Decreto 118/1998, de 23 de junio, de ordenación de la respuesta educativa al alumnado con necesidades educativas especiales, en el marco de una escuela comprensiva e integradora. Boletín Oficial del País Vasco, n. ${ }^{\circ} 130$. España.

\section{Valencia}

- Decreto 131/1994, de 5 julio, del Gobierno Valenciano, por el que se regulan los servicios especializados de orientación educativa, psicopedagógica y profesional.

- Decreto 39/1998, de 31 de marzo, del Gobierno Valenciano de ordenación de la educación para la atención del alumnado con necesidades educativas especiales. Diario Oficial de la Generalitat Valenciana, n. 3224 . España. 